\title{
EL CASO DEL ENDECASÍLABO AGUDO
}

\author{
Por \\ ARCADIO PARDo
}

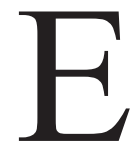

N 1947, la colección Adonais publica el poema de ese mismo nombre de Percy B. Shelley en versión española del poeta Vicente Gaos (parece ser que fue Rafael Montesinos quien propuso se llamara la colección con el nombre del poema de Shelley). Pues bien, en la "Nota preliminar del traductor", Gaos dice que ha procurado no utilizar en su traducción endecasílabos agudos porque «terminan en palabra aguda, que es un final poco eufónico» ${ }^{1}$.

Es, que yo sepa, la última manifestación de una ya muy larga tradición de rechazo del verso endecasílabo agudo. Gaos refleja en esa frase la tendencia que dominaba en los años 40-50 como consecuencia de la restauración de los antiguos credos en la poesía de antes y de después de la guerra. El verso endecasílabo ocupa por esos años una situación preferencial, siendo ese período, como se anunciaba en la presentación del primer número de la revista Garcilaso, Juventud creadora (mayo de 1943-abril de 1946), la "segunda primavera del endecasílabo". En este aspecto, la revista vino a consolidar la tendencia preexistente en los años anteriores, como lo señaló ya su contemporáneo Charles David Ley en el número final de la revista, 35-36².

\footnotetext{
1 Percy B. Shelley, Adonais, Col. Adonais XXXVIII, Madrid, 1947, p. 18.

2 Charles David Ley, "Los poetas de "Garcilaso", in Garcilaso, 35-36, Marzo-abril 1946.
} 
Un sondeo en esta revista nos ofrece sin embargo una sorpresa: la presencia de endecasílabos agudos en bastantes colaboradores de muy diversa índole poética y política. Salvo error, los versos endecasílabos agudos encontrados son los siguientes:

-José María Valverde, "Elegía", n 7 :

por ti llevado, en plena eternidad,

-Pedro Lezcano, "Poema al suelo", n ${ }^{\circ} 19$ :

Quiero aprender a amarte, hozar en ti

-Manuel Segalá, "Oración a Cristo en la Cruz", n 19:

Fuiste crucificado por amor...

¡Señor, Señor: perdónales, Señor!...

Consumido en pecado y en dolor...

si habia de negar tu gran Verdad...

Señor, ¿por qué me diste voluntad...

y estar encarcelado en libertad?...

Yo pequé contra ti, Señor, pequé ...

era un agravio más contra la $\mathrm{Fe}$,

era una nueva ofensa que añadir

a las que recibiste. $Y$ te negué

sabiendo realmente tu existir...

y que moriste para redimir...

de tu cuerpo vencido y en la Cruz...

y a que les ilumines con tu Luz.

Este poema de M. Segalá consta de 100 versos, de los cuales 14 son agudos.

-El mismo, "Cuatro oraciones a los ángeles, I", nº 29:

Voz de angustiado trigo es ya mi voz [...]

Dobladme en vuestros ecos, sed la hoz.

-Julio Garcés, "África", n 20:

y sus piernas cortadas por el sol.

-El mismo, "Noche", n 20:

Mi pecho como una honda canción.

-Demetrio Castro Vilacañas, "Cinco sonetos de la triste ausencia" I, $\mathrm{n}^{\circ} 20$ :

tu fe esperando; porque llegue a mí...

pues si la paz está lejos de ti...

-J. Gallego Díaz, "En su homenaje", n 21 
de un mar de sombra a una clara luz...

lleve yo solo mi pesada cruz.

-Enrique Llovet, "Ser que espera", n 21

de tu cuerpo. Quiero hijo y cristal...

$Y$ el fuego, ¿qué hace el fuego? Está de pie

-Carlos Bousoño, "Elegía de la luz del alma", n²3:

El alma, el tenue hálito de luz

-Ricardo Lezcano, "Árbol plantado", n 26

$Y$ del cielo esa tierna infinitud...

que el camino del óvulo al ciprés

-Carlos Salomón, "Belleza", n²7:

Cómo grita la luna, oh cielo, oh mar

-Chicharro hijo, "Soneto", n 32:

más cerca del morir que del querer...

que este de hoy parécenos de ayer

-El mismo (Sin título), $\mathrm{n}^{\circ} 32$ :

su mejor jamón!, con el pon, pon, pon...

Todo es quita y pon, quita y pon, pon, pon

-Juan Ruiz Peña, "Oda de los eucaliptos", n 33:

Quiero a las blancas nubes ver cruzar

-Juan Pérez-Creus, “...Y mantenerse en pie”, nº 34

Hay un dolor más grave que el Dolor

Esto conduce a pensar que los poetas que colaboraron en Garcilaso y adoptaron la norma que la revista se propuso de dar al endecasílabo una nueva floración, no siempre tuvieron conciencia de participar a la empresa restauradora de los credos clásicos, utlizando, como se ve el verso endecasílabo agudo con una frecuencia que sorprende. El mismo Vicente Gaos se sumó al grupo de la Juventud creadora y colaboró en varios números de la revista con sonetos y también con poemas de otras formas métricas $^{3}$.

${ }^{3}$ Tampoco todos los colaboradores eran adictos a la ideología que representó la $J u$ ventud creadora. Baste citar los nombres del mismo Vicente Gaos, de Pedro Lezcano, de Fernando González, de José Hierro, de José Luis Hidalgo, Carlos Edmundo de Ory, Dámaso Alonso, Vicente Aleixandre, Eugenio de Nora, Luis Landínez, José Luis Cano, Victoriano Crémer, Alfredo de los Cobos, Ramón de Garciasol, Leopoldo de Luis y probablemente de otros cuyas opciones desconocemos. Hay que reconocer que Garcilaso fue una revista ampliamente acogedora y generosa con todos los poetas de la época; algunos de los colaboradores ya eran más adultos que "jóvenes creadores". 
Las censuras contra el verso agudo se refieren en la tradición al endecasílabo, siendo la rima aguda tolerada y enormemente utilizada en los versos de arte menor. Quién no recuerda algún romance o fragmentos de romances en los que los versos pares riman asonantados en vocal tónica.

No ha sido este el caso del endecasílabo agudo que, sometido a polémica sobre su licitud o no licitud en el empleo, ha sido utilizado por algunos de los poetas del XVI (Boscán, Hurtado de Mendoza, Gutierre de Cetina), raras veces por los del XVII y recuperado por los románticos en algunas de sus estrofas de arte mayor.

En la Antología de poetas líricos castellanos, pueden verse las críticas de Don Marcelino ${ }^{4}$ contra los versos agudos de Boscán, y en los trabajos de Emiliano Díez Echarri ${ }^{5}$, y de José Domínguez Caparrós ${ }^{6}$ la opinión de los tratadistas desde el siglo de oro al XIX sobre este asunto.

Un tanto sorprendido por las palabras de Vicente Gaos, he tratado de sondear en la poesía en lengua española de los últimos siglos, y especialmente en la más próxima a nosotros, qué empleo se ha hecho del endecasílabo agudo, si los poetas se atienen a ese desafecto o si, al contrario, lo han adoptado como a los otros endecasílabos y obtenido efectos significativos dentro del poema.

Resulta curioso observar que si el endecasílabo agudo ha sido relegado en épocas anteriores, cuando los poetas lo utilizaron, suelen hacerlo en composiciones con una muy fuerte concentración de este tipo de verso ${ }^{7}$. Algunas composiciones con

\footnotetext{
${ }^{4}$ Marcelino Menéndez Pelayo, Antología de poetas líricos castellanos, Madrid, 1919, T. XIII, pp. 219-220.

${ }^{5}$ Emiliano Díaz Echarri, Teorías métricas del siglo de oro. Apuntes para la historia del verso español, Madrid, R.F.E., Anejo XLVII, Madrid, 1970.

${ }^{6}$ José Domínguez Caparrós, Contribución a la historia de las teorías métricas del siglo XVIII y XIX, Madrid, R.F.E., Anejo XCII, 1975

${ }^{7}$ Por ejemplo en estos versos de Diego Hurtado De Mendoza, BAE, Poetas líricos de los siglos XVI y XVII, I, Madrid, 1950, p. 52.

Cantar vi a Melibea y a Damón,

Entrambos aquejados de pasión,

Iguales en cantar y responder,

Iguales en quejarse con razón.

Olvidan los ganados el pacer,

Y los montes inclinan el altura

$\mathrm{Y}$ detienen los ríos el correr.
} 
endecasílabos agudos suelen ser de tipo jocoso que era uno de los casos tolerados por los tratadistas. Así, el Licenciado Francisco López de Úbeda pone al frente del "Número tercero" de la "Introducción general" de La Pícara Justina un "Soneto de pies agudos al medio y al fin", en endecasílabos agudos, aunque no siempre respeta el pie agudo en medio del verso ${ }^{8}$.

En el siglo XVIII encontramos otros dos casos de composiciones, también sonetos, satírico-jocosos escritos totalmente en endecasílabos agudos. El de Gerardo Lobo se llama "Receta para ser un gran soldado"; y el del fabulista Tomas de Iriarte, "Tres potencias bien empleadas en un caballerito de estos tiempos".

Hay que reconocer que esas composiciones están muy lejos de ser ejemplos de alta calidad poética.

La recuperación del endecasílabo agudo se realiza en el XIX; Bermúdez de Castro creó la octava aguda en la que los versos 4 y 8 rimaban entre sí con terminaciones oxítonas; Zorrilla las utilizó en algunos poemas. También pueden encontrarse en esa época sextetos con algún endecasílabo agudo.

Los poetas modernistas utilizaron rimas agudas especialmente en versos alejandrinos, dodecasílabos, decasílabos, pero es poco frecuente el uso del endecasílabo agudo. La irrupción de los versos mayores agudos aparece desde $\mathrm{Azul}$ en numerosos poemas.

Son fecuentes los casos de empleo de rimas agudas en versos mayores no endecasílabos y combinaciones internas que ofrecen materia de análisis. Este dodecasílabo del poema "Líbranos, Señor", por ejemplo, de Rubén Darío, ofrece una interesante concentración de agudos y un esdrújulo en contigüidad con el agudo final. Los agudos internos riman con el situado en final del verso dándole una notable contundencia:

$$
\text { de dolor y amor, líbranos, Señor }
$$

comparable a este tridecasílabo del poema IV de "Los Cisnes":

\footnotetext{
$\overline{8}$ "Número tercero" de la Introducción, en La novela picaresca española, Madrid, Aguilar, 1956, págs 718-719.

${ }^{9}$ Pueden verse estos sonetos en Poesía del siglo XVIII, Ed. de John H. R. Polt, Madrid, Castalia 65, 1994, págs. 49.y. 227
} 
del ruiseñor primaveral $y$ matinal

O también esta otra experimientación consistente en situar vocablos agudos no sólo en situación de rima sino también bajo el acento final de hemistiquio, como ocurre en los docecasílabos en tercetos monorrimos del poema "Líbranos, Señor" ya citado ${ }^{10}$.

Pero repetimos que si la utilización de versos agudos es frecuente en Rubén Darío, en cambio los endecaslabos agudos son todavía escasísimos, quizá por el desdén que la tradición le ha infligido. En "Divina Psiquis", en la parte compuesta a modo de silva, aparece este endecasílabo:

repartes tus dos alas de cristal

y en "Oh, miseria de toda lucha por lo finito", este otro:

que dura lo que dura el perfumar.

Otro poeta hispanoamericano, intensamente modernista, Julio Herrera y Reissig, gran experimentador de ritmos, utiliza el endecasílabo agudo en el poema "El beso" compuesto por treinta y ocho endecasílabos con dos únicas rimas alternadas en -eso e -ir.

$\overline{10} \quad$ En la fresca flor, en el verso sutil;

el triunfo de Amor en el mes de Abril;

Amor, verso y flor, la niña gentil. (Terceto $2^{\circ}$ )

Oh, saber amar es saber sufrir,

amar y sufrir, sufrir y sentir,

y el hacha besar que nos ha de herir. (Terceto $4^{\circ}$ )

Líbranos, Señor de Abril y la flor,

y del cielo azul y del ruiseñor,

de dolor y amor, líbranos, Señor. (Terceto $6^{\circ}$ )

Nótese también la concentración de palabras agudas en el verso «amar y sufrir, sufrir y sentir». Otro ejemplos de concentración de agudos es el siguiente:

Dejad al huracán mover mi corazón

del poema "De otoño".

${ }^{11}$ Para la versificación de este poeta puede verso nuestro estudio MADELINE y ARCADIO PARDO, "Sobre la métrica en la obra poética de Julio Herrera y Reissig", en Julio Herrera y Reissig, Poesía completa y prosas, Madrid, París, México... ALLCA XX, 1998, págs 1083-1162. 
La mayor parte de los versos pares son agudos, mientras los impares son llanos, aunque el poeta modifica el orden algunas veces:

Si has sabido besar, di: ¿que es un beso?

-Es fuego en dulce, es vida en elixir;

Un juramento de ventura impreso

Con lacre ardiente en mudo confundir,

Rosada eucaristía, ideal suceso;

Pentecostés de dulce redimir...

Este poema es de 1906 y se publicó por primera vez en $L a$ Democracia de Montevideo. El periódico elogia las cualidades del poeta, pero también dice que en este poema la inspiración "se ha visto esclavizada por dos rimas consonantes" 12 Este poema revela, como otros de esa época, cierta torpeza todavía en el empleo del endecasílabo agudo y como una falta de familiaridad con él.

Un caso curioso se presenta en el "Canto a Lamartine", silva aconsonantada en el que aparecen varios endecasílabos agudos en versos contiguos:
Tu casta poesía
Vivirá mientras haya juventud, Mientras que pueda el alma sollozar, Mientras inspire gloria la virtud, Mientras derrame un beso de armonía El corazón humano al despertar!

Pero estos poemas petenecen a la primera época de Herrera que Ángeles Estevez denomina como "prehistoria" de su obra" ${ }^{13}$.

En el soneto "Determinismo ideal", incluido en Lunas de oro, el terceto final tiene dos versos en rima aguda ${ }^{14}$.

\footnotetext{
${ }^{12}$ Véase Ángeles Estevez, en Julio Herrera y Reissig, Poesía completa y prosas, op. cit., pág. 284, nota 20.

${ }^{13}$ Ibid.

${ }^{14}$ Caía desde el cielo un gran borrón...

Y nos volcamos bajo un beso largo,

Todos los astros en el corazón.
} 
En "Nieve floral" se incuyen otros dos endecasílabos agu$\operatorname{dos}^{15}$.

Como se ve, en la obra de Rubén Darío y en la de Julio Herrera y Reissig, el endecasílabo agudo es muy poco utilizado, mientras que los versos mayores oxítonos son, no sólo abundantes, sino que en ellos los poetas saben obtener efectos variadísimos enriqueciendo la armonía y el significado.

Leopoldo Lugones utiliza algo más el endecasílabo agudo, pero aunque adquiere este verso en su obra más naturalidad y soltura, se observa que su empleo se ciñe casi siempre al tipo de estrofa de serventesio, como si todavía no osara ocupar otras posiciones dentro de la variedad estrófica de los poemas. Tanto es así que se puede clasificar el uso del endecasílabo agudo en Lugones en dos grupos: 1) endecasílabos agudos incluidos en serventesios, versos 2 y 4 ; y 2) endecasílabos incluidos en otras estrofas o en verso libre rimado, que, como se sabe, fue modalidad inventada por Lugones.

1) endecasílabos incluidos en serventesios, versos 2 y 4 :

"Olas grises", de Libro de paisajes (1917), se compone de tres serventesios, el tercero de los cuales tiene rimas agudas en los versos pares ${ }^{16}$.

Once serventesios endecasílabos forman el poema "Los tordos", también del Libro de paisajes; las estrofas pares tienen rimas agudas en los versos 2 y 4 . Hay, pues, una alternancia entre estrofa con rima llana y estrofa con rimas agudas en versos pares, con un total de cinco estrofas de este tipo y por lo tanto diez endecasílabos agudos ${ }^{17}$.

$\overline{15}$ Te oscurece el disfraz, pero sé

Que eres ave que busca mis rejas,

En tus risas yo sé que te quejas...

Ven,tu orgullo es el Dios de mi fe!

16 Sigue lloviendo. El día es triste y largo.

En el remoto gris se abisma el ser.

Llueve... Y uno quisiera, sin embargo,

Que no acabara nunca de llover.

In Leopoldo Lugones, Obras poéticas completas, Madrid, Aguilar, 1959, pág. 546.

17 Segundo serventesio:

Poco a poco, otro trino se levanta,

Y otro, otro y otros, en concierto tal, 
"El martín pescador" (Id.) tiene sólo dos estrofas en verso endecasílabo; también aquí los versos pares son agudos, pero con rima independiente en cada uno de los dos serventesios ${ }^{18}$.

Otro poema de dos estrofas en endecasílabos con rimas agudas en versos pares es "Éxtasis" (Id.); cada estrofa tiene rimas dis$\operatorname{tintas}^{19}$.

El largo poema "El dorador" (Las Horas doradas, 1922) se compone de 27 serventesios endecasílabos) tiene tres estrofas con agudos en los versos pares. Citamos en nota el último de estos tres serventesios ${ }^{20}$.

También son servestesios las dos estrofas de "Alba sonora" (Id), en el segundo de los cuales hay dos versos agudos ${ }^{21}$.

"Elegía crepuscular" (Romancero, 1924) ofrece once serventesios; la última estrofa tiene los pares agudos ${ }^{22}$.

\footnotetext{
Que parece que todo el árbol canta

Cual si se hubiera vuelto de cristal.

In Id., pág. 582.

18 Sobre el remanso azul, agudo acecha

Desde un lánguido gajo del sauzal,

En inminente inclinación de flecha,

La lentitud profunda del caudal.
}

Oro de sol en la corriente boya...

Y destellando un súbito arrebol,

Identifica el pájaro en su joya,

Sauce verde, agua azul y oro de sol.

In Id., pág. 593. Nótese la contigüidad de un vocablo esdrújulo y de uno agudo en rima en el verso: «Y destellando un súbito arrebol». Este empleo reaparece con cierta frecuencia en poetas posteriores como se verá en su lugar.

${ }^{19}$ In Id. pág. 595.

20 Silencio que recóndito y dorado, Con tu recuerdo llorará después, La poesía del nido abandonado En el noble misterio del ciprés.

Id. págs. 611-614.

${ }^{21}$ Nótese en el segundo endecasílabo la contigüidad de palabra esdrújula y palabra aguda en rima:

En la distancia azul, de cuando en cuando,

Ladra un perro con júbilo agresor,

Y cordialmente el día va dorando

La soledad dichosa del pastor.

Id., pág. 700 .

22 Glorioso en mi martirio, sólo espero

La perfección de padecer por ti.

$\mathrm{Y}$ es tan hondo el dolor con que te quiero, 
2) endecasílabos incluidos en otras estrofas o en verso libre rimado:

En "El Aracucú" (Libro de paisajes) el poeta compone tres quintetos endecasílabos con dos versos agudos en cada estrofa, repitiendo el segundo los mismos sonidos del título. Seis endecasílabos agudos más. El verso final del primer quinteto es:

Llora la selva: Ar...rra, cu-cú, cu-cú.

La sección "Las ciudades" del libro Odas seculares (1910) comprende tres poemas titulados "A Buenos Aires", "A Montevideo" y "A Tucumán". Los tres están escritos en octavas bermudianas (ABBĆ DEEĆ) o sea con la misma rima aguda en los versos 4 y 8 . Son en total veinticinco octavas y por lo tanto cincuenta endecasílabos agudos.

Sabido es que Lugones experimenta igualmente la utilización de versos de medidas muy distintas, incluso sin medida regular, a modo de verso libre, pero con rima. En "Loa del fuego alegre", incluido en Poemas solariegos (1927), ${ }^{23}$ composición relativamente larga, se ofrece este ensayo; por lo cual aparecen en él algunos endecasílabos y endecasílabos agudos sin obedecer a norma en su distribución. Algunos espigados en el poema son los siguientes:

Y el haragán, el feligrés

Que se calienta el alma por los pies.

La salamandra que usted puede ver

Cada tres siglos como es menester.

Cósmico huevo de la eternidad

Misterio de las estrellas

Más antiguas que el tiempo y la verdad.

Es la hora en que como a una mala acción

\footnotetext{
Que tengo miedo de quererte así.

Id., pág. 753.

23 In LeOPOLdo Lugones, op. cit., págs 818-822.
} 
Baja a beber el perro cimarrón.

No es raro encontrar por otra parte en estos poemas versos agudos contiguos de medida distinta como ocurre en algunos de los ejemplos citados. He aquí un decasílabo en contigüidad con un endecasílabo:

Que instalado en el mismo rincón, (decasílabo)

Cazando moscas paga su pensión. ${ }^{24}$ (endecasílabo)

La frecuencia del endecasílabo agudo en Lugones es algo mayor que en los poetas Darío y Herrera y Reissig, pero aún así diríase que el poeta, ya sea por respeto a la tradición, sea por falta de fluidez, utiliza ese versos pocas veces, cuenta habida de la extensión de su obra, mientras que, como en los otros poetas citados, sus versos mayores revelan una gran riqueza de posibilidades a partir de rimas agudas o vocablos agudos internos e incluso en convivencia con esdrújulos.

Hemos hecho un sondeo también en la obra de otros poetas hispanoamericanos tales como Gabriela Mistral, Juana de Ibarburu, Salvador Díaz Mirón, Rafael López Velarde; en estos poetas aparecen también algunos endecasílabos agudos pero no como vehículo de expresión preferente ni frecuente. Damos, sin embargo, un cuarteto del último de los poetas citados, de su poema "Huérfano" por haberse utilizado en él todas las rimas en agudos:

Huérfano quedará mi corazón alma del alma, si te vas de ahí, y para siempre lloraré por ti enfermo de amorosa consunción.

Tres poetas mayores, Unamuno, J. R. Jiménez y Jorge Guillén van a utilizar el endecasílabo agudo liberándole de las trabas que la tradición le imponía. Este verso adquiere en la obra de estos poetas una dimensión excepcional.

$\overline{24 I d}$., pág 916. 
Puede decirse que el endecasílabo agudo entra realmente en la poesía en lengua española del xx con Miguel de Unamuno.

Ya en Poesías (1907) Unamuno pone en un endecasílabo sáfico palabras agudas bajo los acentos principales en $4^{\mathrm{a}}$ y $8^{\mathrm{a}}$ posiciones, aunque el verso no tenga rima oxítona:

\section{No busques luz, mi corazón, sino agua}

revelando así un instinto seguro en la elección de los componentes del verso. En el mismo poemario aparece este otro verso que anuncia ya la dimensión que el poeta va a dar a los vocablos agudos en posición final:

que a oscuras fluye de la eternidad

"La ley del milagro" de Rosario de sonetos líricos (1912) termina con estos tercetos:

Dios a dos manos teje su telar; con la zurda llevando el recio trazo que el hombre a ciencia logra sujetar,

mientras su diestra en ese cañamazo borda el santo capricho del azar que es del progreso el poderoso brazo.

En el poema "En Gredos" incluido en Andanzas y visiones españolas, silva aconsonantada, se encuentran algunos endecasílabos agudos:

templo de nuestro Dios, jel español!.....

la que orea la frente a tu Almanzor....

buscando al sol en mutua soledad....

bajan cantando ríos de frescor....

Rimas de dentro aparece en 1923. De su poema "En estas tardes pardas" entresacamos este verso:

que mece el alma de la eternidad 
con la palabra eternidad también aquí realzada en posición final.

El endecasílabo agudo aparece con mayor frecuencia en Teresa, (1924). Algunos de los poemas de este libro son breves, y los versos pares riman entre sí. Este es el caso de los poemas 3 y 8 compuesto cada uno de ellos por doce endecasílabos. En ambos poemas la rima en los versos pares es en $\mathbf{A R}$, a excepción del verso 8 del primero que tiene en posición final la palabra "edad".

Los versos pares del poema 3 son los siguientes:

de tu pecho anheloso el palpitar...

el misterio de aquella sed de amar...

aquel gesto de angustia de agarrar...

los ensueños floridos de tu edad...

donde se oye la canción del mar...

iy la canción se llama recordar!

Los versos pares del poema 8 tienen la consonancia regular:

refrescaba tus sienes al volar...

sobre tu tierra vuelan sin cesar...

espinas le quitaron al azar...

del corazón que se me va a parar...

trayéndome recuerdos al pasar...

bajo que has ido al fin a descansar.

El poema 34 ("Déjame de pensar...") está formado por siete cuartetos con rima consonante, el último de los cuales presenta sus cuatro versos con rima aguda:

Callaste, y yo pensaba, ¿cómo no?

El querer era en mí pensar..., en ti

pensar era querer... igual... y así

en pensar y querer se nos pasó...

El poema 48 se compone también de siete estrofas con la diferencia del anterior de que aquí las estrofas son serventesios. Tiene este poema la particularidad de utilizar rima aguda en 
todos los versos pares, pero con independencia de un cuarteto a otro. La presencia de endecasílabos agudos en el poema es por lo tanto elevada puesto que acusa el $50 \%$ de la totalidad de los versos. Se confirma lo dicho anteriormente acerca del vocabulario en posición de final agudo: los vocablos elegidos están en consonancia con las hondas preocupaciones del poeta: inmortal, pasión, corazón, amor, dolor, renacer, vivir, morir. He aquí la primera estrofa:

\section{Tú no puedes morir aunque me muera; tú eres, Teresa, mi parte inmortal; tú eres mi vida, que viviendo espera, la estrella de mi flor breve y fatal.}

Otro poema del mismo conjunto, "Mi madre dijo"... (58), tiene seis serventesios con rimas agudas en los versos pares en todo el poema, pero igualmente con independencia de rima de un serventesio a otro. La primera estrofa es la siguiente:
Mi madre dijo: "Siendo muy chiquito... tenía ella dos años y tú tres..., os hicimos trocar, jusos benditos!, cuatro besos de ruido, y hoy... iya ves!

Citamos de este libro otro poema, "Se muere aquel que ve la cara a Dios" (75). Se compone de endecasílabos y heptasílabos dispuestos en orden irregular, así como las rimas que tampoco obedecen, en cuanto a su distrubución, a un orden determinado. Tiene los endecasílabos agudos siguientes:
Se muere aquel que ve la cara a Dios; vimos la cara a Dios juntos los dos... marchando de tu santa huella en pos.... con tus ojos y en ellos a Dios vi...

Puede decirse que la presencia de endecasílabos agudos en la poesía de Unamuno parece presentar un progreso desde sus Poesías hasta Teresa en cuanto a la frecuencia en la utilización. Pero es arriesgado tratar de establecer una curva ascendente por 
no presentar ese progreso una evolución contínua. En De Fuerteventura a París (1925) el endecasílabo agudo, salvo error, desaparece, como si la estructura rígida del soneto, obstaculizase ese empleo. En cambio en Teresa, donde se encuentran poemas que recuerdan la levedad formal de las rimas becquerianas, la presencia de endecasílabos agudos es bastante mayor.

El Cancionero escrito en su mayor parte en versos largos, con presencia de rimas agudas en muchísimos de ellos, no ofrece ejemplos de endecasílabos agudos.

Mayor importancia tiene el empleo que Unamuno hace del endecasílabo agudo en El Cristo de Velázquez (1920) y que no ha pasado desapercibido por algunos críticos, principalmente por W. Calvin Cannon ${ }^{25}$ y también por Juan Guillermo Renart en su estudio El Cristo de Velázquez de Unamuno: estructura, estilo, sentido ${ }^{26}$.

Importa señalar en primer lugar que este poema termina cada una de las secuencias que componen sus cuatro partes en endecasílabos agudos sueltos, a excepción de muy pocas que se señalan más abajo. Citamos aquí únicamente los versos finales de las secuencias de la parte primera para no consumir demaiado espacio. Son los siguientes:

I.- Sobre la muerte bien de cara a Dios.

II.- dominando el poder del Tentador

III.- reservarme, que no se engaña a Dios.

IV.- de la esperanza en Cristo salvador!

$V$.- se percaten del todo que hombres son.

VI.- y cifra de lo eterno, que es la cruz!...

VII.- de la divina, inmensa oscuridad!

VIII. - y de la vida que no pasa mar!

IX.- iperdón es su lechosa luz lunar!

$X$ - y es tu vida la guerra que da paz!

XI.- porque guerra de paz fue tu pasión.

XII.- en nuestra noche anuncia eterno albor.

XIII. - de haber nacido a pena de morir.

${ }_{25}$ Calvin Cannon, Miguel de Unamuno's El Cristo de Velázquez. Tesis doctoral, Tulane University, 1958, pág. 134.

26 Juan Guillermo Renart, El Cristo de Velázquez de Unamuno: estructura, estilo, sentido, Toronto, Anejos de la Revista Canadiente de Estudios Hispánicos, 1982. 
$X I V$ - cantares vírgenes de eterno amor.

$X V$.- por tu cuerpo, que es arpa universal. XVI.- con el fuego de amor la luz del sol!

$X V I I$ - hiciera con sus manos nuestro pan.

XVIII.- quien le da un sempiterno revivir.

$X I X$. - las almas que brotaron de su sien.

$X X$. cuando con su mirar muerte nos da!

$X X I$. - con tu desnudo pecho por cendal?

XXII.- ¡Rey del desierto, León de Judá!

XXIII.- de tu padre a nosotros el perdón!

$X X I V .-$ sino de vida eterna alta lección!

$X X V$.- ceñidor del castillo celestial!

$X X V I$ - el eco que a la tierra retembló.

$X X V I I .-$ y hágale pavesas su restregón;

XXVIII.-contra la tierra viénense a quebrar!

$X X I X$. y que florezca por la eternidad!

$X X X$. de las aguas corrientes del Jordán.

XXXI.- del hastio y la deseperación.

XXXII.- nuestra divina hambre carnal de Ti!

XXXIII.-donde descansa cuanto vive: jel Sol!

$X X X I V$. de tu manto en el paño sin confín!

$X X X V$.- que depura la broza sin cesar.

$X X X I X .-p o r$ las que rompe de la vida el sol.

Las excepciones en el conjunto son muy pocas:

En Tercera parte, XII:

vasto rosario de constelaciones?

Id. XXIV:

para nacer y así nos engendraste!

En Cuarta parte, III:

de la resurrección de nuestros cuerpos.

Los endecasílabos utilizados como cierre de secuencia aportan con su vocablo agudo como una contundencia, como un definitivo final que Unamuno ha sentido con claro instinto. 
Eso le ha permitido también poner de realce la palabra final de la secuencia y subrayar así, por su sitio preferente, el amplio significado que él le da. El vocabulario utilizado así tiene estrecha relación con el sentido religioso del poeta y del poema. Parece evidente que Unamuno ha escogido ese modo de cierre de secuencia con endecasílabo agudo deliberadamente y eso permite pensar que el poeta concedía a la sonoridad final un significado totalizador que hemos de tener en cuenta en el momento de la lectura del poema.

De los 76 versos agudos finales de secuencia, 27 terminan en palabra monosílaba, 38 en palabra bisílaba, 10 en trisílabas, 4 en cuadrisílabos y alguno en pentasílaba. El vocabulario es eminentemente unamuniano: Dios aparece en cuatro finales de verso, $T u$, cuatro veces igualmente, amor y sol, tres veces, cruz, dos veces. Otros vocablos aparecen una sola vez, pero son también reveladores de las preocupaciones del autor: salvador, oscuridad, pasión, morir, pan, revivir, restregón, triunfador, mortal.

Pero además, como ya señaló Cannon, muchos de esos endecasílabos agudos aportan connotaciones internas que vienen a ser como refuerzos de su significado, sea porque en el interior del verso otro vocablo agudo colocado bajo acento fuerte viene como a anunciar el agudo final:

\section{dominando el poder del Tentador}

sea estebleciendo un contraste de sentido:

y es tu vida la guerra que da paz porque guerra de paz fue tu pasión

o corroborando y reforzando el significado:

con el fuego de amor la luz del sol

La contigüidad de vocablo esdrújulo inmediato al agudo en rima realza la sonoridad de éste último:

de tu volada al místico rumor gotas de la más íntima pasión 
La sucesión de un sonido consonántico sordo en un mismo verso en el que predominan los pies trocaicos tiene igualmente un efecto de fuerte intensidad:

carne que toca y siente, que oye y ve (tocay / siente/ queoyey) al cuello de la muerte cual collar (cuello / dela /muerte/ cualco)

Palabras de sentido complementario bajo los acentos:

se escarchan en blancor de viva luz calma de paz en reposo mortal y fuiste muerte de la Muerte al fin

Cannon ya había señalado algún caso de aliteración como refuerzo del sentido. En el verso siguiente por él citado, se encuentran además de la repetición de la sílaba $p a$, una sucesión de consonantes oclusivas interesante:

¡tierra panera, le pariste tú!

o bien este otro:

en que asidos de Ti, poder flotar!

tupida de dolor, sangre de Dios

o sitúa en proximidad una misma consonante, $m$ en el caso que sigue:

cuando con su mirar muerte nos da

que tiene además la particularidad de precipitar el acento a la sexta sílaba como para exaltar el vocablo siguiente muerte y hacer de ese concepto la sede del verso y de la expresión. Esta palabra está además realzada por la contigüidad de los acentos en $6^{\mathrm{a}}$ y $7^{\mathrm{a}}$ sílabas (mirar muerte) ${ }^{27}$

$\overline{27}$ Para este tipo de endecasílabos, véase ARCADIO PARDO, "El endecasílabo con acentos en $6^{\mathrm{a}}$ y $7^{\mathrm{a}}$ sílabas", in Variations autour de la poésie, Hommage à Bernard Sesé, Thomas Gomez (Ed.), Publications du C.R.I.I.A., Université de Paris X Nanterre, 2001, vol. 2, págs. 87-108. 
En algunos versos aparecen formas paralelísticas o bimembres:

Rey del desierto / León de Judá vida al darnos / la muerte nos darán cantares vírgenes / de eterno amor

De los treinta y nueve versos agudos de cierre de secuencia de la Primera Parte, 15 son de ritmo melódico (acentos en 3-610) lo que revela el equilibrio y serenidad que el poeta veía en el lienzo de Velázquez.

Doce de esos versos son sáficos y cinco heroicos. Algunos tienen un ritmo irregular o poco frecuente.

El primer verso de cierre del poema, o sea, el verso final de la primera secuencia de la primera parte es:

sobre la muerte bien de cara a Dios.

y el último verso del poema, el verso final de "Oración final" es:

mi mirada anegada en Ti, Señor!

«Dios» y «Señor» encuadran así el conjunto de los versos finales, como abriendo y cerrando la estructura de todo el poema.

Por su posición en el poema, por el vocabulario agudo empleado, por la variedad de las sonoridades y de las connotaciones internas del verso, se puede afirmar que el endecasílabo agudo tiene en El Cristo de Velázquez una misión de soporte fundamental.

En la obra de Juan Ramón Jiménez se pueden distinguir dos épocas en lo que respecta al empleo del endecasílabo agudo: la obra anterior a La estación total y las canciones de la nueva luz y la obra que comprende este libro y la posterior.

En la poesía correspondiente al primer grupo apenas se encuentran endecasílabos agudos. Los poemas están escritos sea en versos menores, con numerosas variantes, sea en general en alejandrinos, aunque esto no excluye el que puedan darse versos 
mayores de distinta medida. Los Sonetos espirituales no ofrecen casos de versos agudos.

En el grupo que forman La estación total y las canciones de la nueva luz (1946) y Animal de fondo (1949) que aparece después con el título de Dios deseado y deseante (1957), en cambio, el endecasílabo agudo es no sólo frecuente, sino que se hace vehículo principal del pensamiento del poeta. Se puede decir que la madurez plena del poeta elige ese vehículo de expresión como el más adecuado para la poesía concentrada, esencial que es entonces la suya, poesía que ya no tiene como finalidad la belleza sola, sino el enfrentamiento del poeta con el confín de su vida.

En Baladas de primavera (1910) se encuentran algunos de los versos tan conocidos como éste:

\section{Dios está azul. La flauta y el tambor}

y estos otros dos

Me respondió radiante de pasión yo te querré con todo el corazón.

en los que el acento en vocablo agudo en $4^{\mathrm{a}}$ parece anunciar el agudo final.

Este otro viene formado por una sucesión de vocablos agudos, y terminaciones agudas bajo los acentos en $2^{\mathrm{a}}, 4^{\mathrm{a}}, 6^{\mathrm{a}} \mathrm{y}$ $10^{a}$ sílabas:

¡Amor, la cruz, amor, ya floreció

Citamos a continuación algunos otros simplemente a modo de ejemplo:

¡Sí, en todo vives tú! ¡Mata que fue

de De Apartamiento (1911-12) ("El corazón en la mano"), verso en el que hay acentos en $6^{\mathrm{a}}$ y $7^{\mathrm{a}}$ sílabas, poco frecuentes en este poeta.

En El silencio de oro (1911-1913) se encuentra este otro agudo: 
Di, ¿Qué harás ya si el sol tuyo se fue?

Los cuatro que siguen aquí recurren a la misma palabra en posición de rima:

y parece que el pobre corazón (La frente pensativa, 1911-1912)

Está tan puro ya mi corazón (Eternidades, 1918)

iqué grito de alegría, corazón! (Piedra y cielo, 1919)

como una flor eterna, corazón (Id.)

Otro, del mismo libro:

me pareces que hundes tu troncón

Los endecasílabos agudos espigados en estos libros son en número reducido si se tiene en cuenta la ya muy considerable extensión de la obra, y el vocabulario que se encuentra en posición final parece conservar todavía su parentesco con el de la poesía sentimental tradicional.

Qué distintos son los ejemplos que aparecen en las obras finales del poeta. En ellas el endecasílabo agudo no sólo se hace fecuente, sino que adquiere una densidad expresiva hasta entonces no lograda en este tipo de verso. Diríase que el poeta se identifica ahora más con la forma aguda del verso, que no siempre es en metro endecasílabo, naturalmente, pero que parece indicar una adecuación total entre el pensamiento del poeta y la forma que lo expresa, siempre como mensaje afirmativo, definitivo.

La proporción de endecasílabos utilizados en estos últimos libros es muy superior a la utilizada en los libros anteriores. Pero además se observa un incremento de un conjunto a otro de la obra final. En La estación total y las canciones de la nueva luz se encuentran aproximadamente entre 60 y 70 endecasílabos agudos; en Animal de fondo con Dios deseante y deseado, aparecen enre 100 y 110 . Todo parece indicar que el poeta adopa esa forma (y todas sus variantes) como modo de expresión más íntima, más auténtica, más radical. Se presentan a continuación ejemplos sacados de estos libros últimos tratando de acercarnos a las posibilidades expresivas que el poeta ha obtenido. 
En el poema "El otoñado", de La estación total y las canciones de la nueva luz hay versos plenamente logrados, tanto considerados como unidad expresiva como por las variaciones internas de las sonoridades y de la acentuación. En el que se cita a continuación los sonidos que realzan los acentos tienen una familiaridad vocálica a la que contribuye igualmente la vocal oscura de sombra en sexta posición:

transmito olor, la sombra huele a dios

En este verso la presencia del sentido (olor, huele) concede una impresión de humano acercamiento a lo supraterrenal. En otro verso del mismo poema el sentido del tacto materializa en cierto modo el concepto abstracto de la soledad. La soledad se toca, se hace carnal:

\section{deleito el tacto de la soledad}

La maestría que el poeta ha adquirido se revela, entre otros muchos, en este grupo de versos que sigue al que pertenecen los citados aislados; en cuatro de los versos de ese grupo hay palabras agudas sabiamente colocadas bajo el acento en $4^{\mathrm{a}}$ como ecos o anuncios de los agudos que se encuentran en posición final. Dos de esos vocablos agudos son monosílabos (luz, son) de fuerte concentración, los otros dos bisílabos (olor, sabor) puestos en alternancia. La persona, el ser del poeta se expresa aquí por sus sentidos en una presencia total, como en la encarnación de su "estación total":

Chorreo luz: doro el lugar oscuro, transmito olor: la sombra huele a dios, emano son: lo amplio es honda música, filtro sabor: la mole bebe mi alma, deleito el tacto de la soledad

Estos vocablos agudos bajo el acento en $4^{\mathrm{a}}$ prolongan esa sílaba acentuada separando en cierto modo los dos componentes del verso, haciendo de esos vocablos agudos elementos 
fundamentales. Para mayor claridad se transcriben a continuación separando los dos fragmentos del verso:
Chorreo luz: doro el lugar oscuro, transmito olor: la sombra huele a dios, emano son: lo amplio es honda música, filtro sabor: la mole bebe mi alma, deleito el tacto de la soledad

No escasean ejemplos en los que el poeta pone en contacto una palabra esdrújula con la voz aguda final, recurso ya utilizado por otros poetas anteriormente, pero que tienen efectos de sonoridad y de significado. He aquí algunos de ellos:

$$
\begin{array}{ll}
\text { exaltando su última verdad } & \text { ("Paraíso") } \\
\text { que fija con su nítida quietud } & \text { ("Ciudad del cielo") }
\end{array}
$$

Tampoco faltan casos en que el vocablo esdrújulo se situa en posición anterior dentro del verso, como estableciendo un equilibrio sonoro:

$$
\text { y en súbita cascada de fulgor ("Otro desvelo") }
$$

Pueden aparecer igualmentre dos versos contiguos siendo uno de ellos esdrújulo y el otro agudo, como probable efecto de compensación rítmica:

Si lo eterno es instante jeternidad perfecta, fiel con la promesa mágica ("En flor")

la roca abre un crujir, desviación de la tierra dormida por su órbita ("Otro desvelo")

Se podría decir que a veces hay como una "contigüidad a distancia" cuando el esdrújulo y el agudo se han separado por otras palabras, pero situados en posición relevante de inicial y final que encuadran la expresión interior: 
Álamos agrupados

en la fuente de agua elemental ("Ciudad del cielo")

En "La plenitud" hay un ejemplo de concentración de palabras agudas que dan al verso fuerte densidad expresiva; también aparecen en él dos monosílabos oxítonos bajo los acentos en $6^{\mathrm{a}} \mathrm{y}$ $7^{\mathrm{a}}$ que puede aducirse como ejemplo de expresión de intensidad del endecasílabo con acentos en esas posiciones:

$$
\text { El color es más él, más sólo él (Id.) }
$$

Imposible resulta citar todos los ejemplos interesantes. Nos limitamos a unos cuantos:

volar, pasar, morir de flor y amor (Poema "Aurora") dichoso de pasar $y$ repasar ("Criatura afortunada")

que vamos a saltar del cielo al mar que vamos a volver, volver, volver (Id.)

contra el fresco verdor primaveral (Poema "Belleza mayor")

No será en otro abril mejor color, olor mejor, mayor felicidad de vida en flor que en este alto abril (Poema "En flor")

También puede ocurrir que el verso se inicie y termine con palabra aguda, formando a veces una bimembración en la que los elementos componentes obedecen a simetrría:

\section{Pabellón vivo, firme plenitud ("El oasis")}

El ejemplo que sigue utiliza palabras de la misma derivación con efecto de insistencia y de sorpresa en muerto / inmortal:

el vivo muere, el muerto es inmortal ("Aurora")

En el conjunto Animal de fondo se observa que el empleo de palabras esdrújulas disminuye, mientras que las agudas tiene una 
frecuencia mayor que antes. Vamos a limitarnos a dar algunos ejemplos que corroboran lo ya dicho para La estación total:

en este sol azul del sur de luz dios hoy azul, azul $y$ más azul ("Sin tedio ni descanso") igual que el dios de mi Moguer, azul ("Conciencia hoy azul") un ser de luz, que es todo y sólo luz, luz vividora y luz vivificante; una conciencia diamantina en dios Mar verde y cielo gris $y$ cielo azul este término hermoso, cegador

(“Que se ve ser)

("En lo mejor que tengo")

Dejamos el sondeo en Animal de fondo por no alargar demasiado este trabajo, citando un grupo de versos en los que la palabra final es un pronombre monosílabo (tú, yo) y la primera persona del verso estar (estoy). Son cinco versos de los cuales el primero no es endecasílabo, pero que se incluye para no destruir el efecto del grupo. Los tres agudos internos (sentir, gozar, gritar) tienen la sílaba oxítona en $6^{\mathrm{a}}$ posición como anuncia del aguno final:

Lo eras para hacerme pensar que tú eras tú, para hacerme sentir que yo era tú, para hacerme gozar que tú eras yo, para hacerme gritar que yo era yo en el fondo del aire en donde estoy

("Soy animal de fondo")

Ejemplos similares se encuentran en Dios deseante y deseado:

¡Qué infancia universal, qué yo de dios

En el sinfín abierto, allí, sí, allí
(“La menuda floración")

("Y en oro siempre la cabeza alerta")

Recogemos igualmente un caso de bimembración en el que el monosílabo $l u z$ se realza bajo los acentos en $1^{\mathrm{a}}$ y $6^{\mathrm{a}}$ y la variante vividora / vivificante contribuyen a darle una armonía singular: 
luz vividora $y$ luz vivificante

De La estación total a Dios deseado y deseante se observa un incremento en la utilización de terminaciones agudas. Las complejidad observada en las relaciones internas del verso se mantiene, se desarrolla dando al sentido una intensidad grande. El poeta ha ampliado las posibilidades de su lengua poética. Podría decirse con un verso suyo de este último conjunto

que yo ensanché para este niñodios. ("La menuda floración”)

Y también que el endecasílabo agudo, en esta etapa final del poeta, se funde con su aspiración, "en igualdad segura de espresión", identifica verso y luz:

mi luz, mi misteriosa luz, mi luz (En igualdad segura de espresión”)

Así como en "El Cristo de Velázquez" de Unamuno el endecasílabo agudo más frecuente es el melódico, en la obra final de Juan Ramón Jiménez son los endecasílabos con acento en $4^{\mathrm{a}}$ sílaba o en $6^{\mathrm{a}}$ sílaba los más numerosos, coincidiendo en general esas posiciones con monosílabo o con la sílaba acentuada de palabra aguda, por ejemplo en los versos que siguen:

igual que el dios de mi Moguer, azul (acento en $4^{\mathrm{a}}$ ) para hacerme sentir que yo era tú, (acento en $6^{\text {a }}$ )

que aportan por lo abrupto de sus sonoridad un significado de contundencia, de afirmación, de expresión ya intocable.

El tercero de los poetas mayores citados es Jorge Guillén. El número de endecasílabos agudos que hemos encontrado en su obra es elevado. Salvo error, esos versos aparecen en la obra de este poeta como sigue:

$\begin{array}{lr}\text { En "Cántico" } & 118 \\ \text { En "Clamor": } & 116 \\ \text { En "Homenaje" } & 128 \\ \text { En "Yotros poemas" } 120 \\ \text { En "Final" } & 97\end{array}$


que suman un total de $579^{28}$. Por otra parte el número de endecasílabos de cada uno de sus libros no presenta diferencia notable, sino al contrario, su empleo parece totalmente equilibrado de una obra a otra. El libro Final, que es menos extenso, acusa un número menor de endecasílabos agudos. Citamos algunos que nos parecen característicos del poeta:

A plena luz la calidad de ser

De sentir que voy siendo en plenitud

Un ámbito de tarde en pefección

Mi ser una centella. Soy mortal

Mi sangre como un río que es un don

Nos ahogas, cruel inmensidad

Hobre y mujer en plenitud de ser

Porvenir en alud de realidad

Poniendo una esperanza más allá

¿No hay ninguna razón para morir?

La vida es heces, heces, nuestra hez

El ser en plenitud hacia la luz

Es justo que me anule yo también
(Cántico, "Paso a la aurora")

(Id., "Más verdad")

(Id., "Tarde mayor"),

(Clamor, "Soy mortal")

(Id., "Huerto de Melibea")

(Homenaje, "Al margen de Góngora")

(Id., "Al margen de D. H. Lawrence")

(Id., Sin título)

( $Y$ otros poemas, "En estos años de tormentas")

(Id., "Al margen de Garcilaso")

(Final, "Maneras de respirar, III)

(Id., "Los desvelados")

(Id., "Fuera del mundo, 6)

Algunos de los endecasílabos agudos tienen todas sus palabras agudas:

Conocer, escalar aquel sillón

(Cántico, "Feliz insensato)

Creación, creación, más creación (Id., "Aquel instante")

Cavar, podar, arar, ensarmentar (Id., "Dimensión de Sancho")

En otros versos las asonancias internas en sílabas tónicas parecen establecer una gradación de sentido (id / fin):

Con vuestras hadas id a vuestro fin (Homenaje, "Jean Cassou") ¿No nos consuelan más verdad y paz? (Id.)

La contigüidad de esdrújulos y agudos produce un efecto sonoro intenso:

Capital monosílabo, tú, tú (Y oros poemas, "Sucesos en el jardín")

28 Utilizamos la edición de Aire nuestro en cinco volúmenes que corresponden a los títulos Cántico, Clamor, Homenaje, Yotros poemas y Final, Valladolid, Centro de creación y estudios Jorge Guillén, Diputación de Valladolid, 1987. 
Dos palabras agudas situadas en posiciones inicial y final de verso, como encuadrando su contenido, suelen aparecer a menudo:
Manantial inmediato en creación
(Id., "Reviviscencias 60")

A veces se utilizan dos endecasílabos agudos seguidos:

Que el posible entre el hombre y la mujer.

Amor, amor, mañana como ayer (Homenaje, Sin título)

Obra maestra él mismo con la edad,

¿Dirá a sus manos, basta, descansad? (Y otros poemas, "Maestría del viejo laborioso")

Las relaciones internas en el verso pueden ser complejas (Besar / besada; ser / bien):

Besar $y$ ser besada bien, ¿por qué (Id., "Esa boca")

Un acercamiento al vocabulario agudo sitiuado en posición final del verso revela la estrecha relación entre este tipo de versos y el significado de la obra de Jorge Guillén. Palabras como ser, realidad, libertad, plenitud y otras ponen de relieve esa relación y al mismo tiempo exaltan el significado de esos conceptos dentro del conjunto de la obra guilleniana. Sirvan de ejemplo los versos citados a continuación:

SER, 11 casos:

$Y$ arraigarse en el ser y ser iSer, ser! (Cántico, Soneto "Sueño abajo")

De consumar la plenitud de ser

A plena luz la calidad de ser

No hay sonreír más esencial a un ser Que no deja de erguirse hacia su ser Maravillosamente sólo un ser (Id., "Dedicatoria a Pedro Salinas")

(Clamor, "Paso a la aurora")

(Id., "El Infante, II")

(Id., "Tu más allá")

(Id., "Soy mortal")

Hombre y mujer en plenitud de ser

(Homenaje, "Al margen de

D.H. Lawrence") 
Dijo el hombre consciente de su ser. (Y otros poemas, "En estos años de tormentas", 30)

Temiendo están a quien les dio su ser (Id., "Creador y creación")

Se limita a no ser quien pudo ser (Id., "Epigramas, VII")

Triunfa por fin la plenitud del ser (Final, "La expresión, 32")

REALIDAD, 9 casos:

De esta culminación de realidad Vocablo tan mascado es realidad Llega a ser la nombrada realidad La realidad manaba realidad Sin embuste, profunda realidad Porvenir en alud de realidad Cerrado, sustraído a realidad

Que confunden teatro y realidad. ¿Era siempre inferior la realidad

$M A R, 8$ casos

Que son un río solo como el mar Océanos, el mar, un solo mar. Hacia la voluntad. El mar, el mar

Yo con mi verso como el pez al mar "Rayo resbaladizo sobre el mar"

Flota en río que tiende hacia ese mar Pasa y perdura como piedra y mar. Firme esclarecedora sobre el mar
(Cántico, "El concierto.")

(Clamor, "Potencia de Pérez"

(Id., "Aquellas ropas chapadas")

(Id., "Una iluminación")

(Id., "El lío de los líos")

(Homenaje, sin título)

(Y otros poemas, "El prodigio sin magia")

(Id., "En estos años de tormentas")

(Final, "La realidad y el fracaso")

(Cántico, "Luz natal, II”)

(Id., "Luz natal, IV")

(Homenaje, "Al margen de

Os Lusiadas")

(Homenaje, "El agnóstico")

(Y otros poemas, "Nocturnos 2")

(Id., "Cisne sin Leda")

(Id., "Epigramas VII")

(Id., "Reviviscencias")

\section{YO, 7 casos:}

Ni la tarde, tan libre -como yo

Dimensión del espejo: yo más yo
(Cántico, "Contemplación concreta")

(Homenaje, "Bajo la lluvia de fuego") 
Que hoy fuese ayer,

¿Y cómo yo soy yo?

Su soledad, su dios, su Yo, Yo, Yo. (Y otros poemas, "Al margen de

Con orgullo se dice: "Yo soy yo ¿Hasta dónde se llega con su Yo?

Afirmando: "Aquí, aquí estoy yo

(Id., "Tiempo y tiempo V. 14")

Valéry, VI")

(Id., "Yo soy")

(Final, Dentro del mundo, I")

(Id.., "Niñez II")

\section{JARDÍN, 7 casos:}

La hierba en los declives de un jardín Al interés furtivo de un jardín En el retiro umbrío de un jardín Escalando la tapia del jardín

Paraíso muy lejos? No. Jardín

Si de pronto no surge en el jardín
(Cántico, "Además")

(Clamor, "En obra")

(Id., "Tu más allá")

(Homenaje, "Al margen de Bécquer")

(Y otros poemas, "Cántico, 6")

(Id., "Reviviscencias")

No hay nadie en esta plaza que es Jardín (Final, Epigramas, III)

\section{CLARIDAD, 4 casos:}

Reconcentrada ya en la claridad Amorosa invasión de claridad Alza de juventud en claridad Bárbara ya explosión de claridad
(Cántico, "Otoños")

(Cántico, "Luz natal, IV")

(Clamor, "Una iluminación")

(Y otros poemas, "Cántico, $16 ")$

\section{CREACIÓN:, 4 casos:}

Creación, creación, más creación Manatial inmediato en creación

Fiat lux". Dios es Dios de Creación En relación de amor y creación"
(Clamor, "Aquel instante") (Y otros poemas, "Reviviscencias 60")

(Final, "Vida de la expresión, 1 ")

(Id., "Fuera del mundo, 2") 
LUZ:, 4 casos:

No soy sombra grotesca de Su Luz

El ser en plenitud hacia la luz Maldito el día en que naci a la luz Que fatalmente impulse hacia la luz
(Clamor, "Luzbel desconcertado")

(Final, "Los desvelados")

(Id., "Job, múltiple doliente, I") (Id., "Inspiraciones")

SÍ, 4 casos:

La ternura de un largo, lento sí

Los árboles conviven entre sí Habré dicho a la vida un firme sí
(Clamor, "El amor y la música")

(Id., "Susana y sus jardines") (Y otros poemas, "Cántico, $41 ")$

Que nos brinda su encanto porque sí (Final, "Epigramas")

La adecuación del endecasílabo agudo a la obra guilleniana es tan evidente, que se podría condensarse todo esto en uno de esos endecasílabos de Cántico:

\section{tanta armonía a punto e vibrar}

Gerardo Diego, de la misma generación que J. Guillén, ha sido un atrevido experimentador de versificación; pero respetando, en la mayor parte de su obra, a excepción de algunos libros en verso libre, las formas tradicionales. Este poeta nos ofrece, como se verá en Rafael Alberti, la misma tendencia al no empleo del endecasílabo agudo sino en pocos casos. Hemos preferido ceñir nuestro sondeo a las antologías establecidas por el poeta por ser la obra más asequible actualmente, o sea, Primera antología de sus versos ${ }^{29}$ y la Segunda antología de sus versos ${ }^{30}$. Estos conjuntos ofrecen un número elevado de poemas que nos permiten poder encontrar suficientes ejemplos para dar idea de

\footnotetext{
${ }^{29}$ Gerardo Diego, Primera antología de sus versos, Buenos Aires, México, Col. Austral, 219, 1947.

${ }^{30}$ Gerardo Diego, Segunda antología de sus versos, Buenos Aires, México, Col. Austral 1394, 1967.
} 
la alta o baja frecuencia del empleo del verso que nos interesa. Encontramos el primer ejemplo en "Hoy", del libro Imagen:

que ya tiembla de verse junto al mar

y este otro poco afortunado:

y aunque sabe que no puede nadar

o este que sigue, igualmente poco atractivo:

y el cangrejo de premio a su virtud

En la Segunda antología, el empleo es más frecuente, pero escaso comparado con el muy alto número de versos que forman la antología. En el poema "Psique", silva en versos suelto, se encuentra éste:

sentado, casi echado en el jardín...

El poema "Sólo el fin", del conjunto Amor solo es también una silva de versos sueltos en la que se incluye un verso pentasílabo; en ese poema hay dos endecasílabos agudos:

en el puntal insomnio de las tres...

me hablabas disfrazándote en mi voz...

Hay una tendencia en Gerardo Diego a poner en posición final aguda palabras monosílabas como aparecen ya en los dos versos citados. He aquí otros ejemplos:

Sonata en Sí mayor, en Sí o en ti

como llamas subiéndome hasta el Sí

Tú me interpretas, tú también en Sí

No. Tú, Amor mío, no eres ellas, no Mar de mi costa, mar, mar, mar, mar, mar

cata el verdor diáfano del ser Mar, mar y mar, sí, padremadre mar que al Ebro pudo apacentar o al Pas siempre distinta y a su mente fiel
(Amor solo, "Sonata en Sí mayor")

(Ibid.)

(Ibid.)

(Amor solo, "Amo solo")

(Mi Santander, mi cuna, mi palabra, "El padremadre mar")

(Id., "El padremade mar")

(Id.)

(Id.)

(Vuelta del peregrino "La mirada de Ortega") 
Estos versos de final monosílabo ponen de manifiesto los tres temas que dominan la obra de este poeta: el amor, el mar, la tierra natal.

Los otros no terminados en vocablo monosílabo son ocho en esta Segunda antología, con un total de veinte versos que resulta ser una proporción baja dado el número total de versos de la antología.

Solamente ocho versos de los que nos interesan hemos encontrado en el Libro de poemas (1921) de Fedrico García Lorca, siendo este libro el primero de los suyos. El endecasílabo agudo desaparece en su obra posterior casi completamente. En Poeta en Nueva Nueva York han aparecido dos, pero en poemas en verso irregular. De modo que puede decirse que este verso está casi ausente en la obra de este poeta.

Rafel Alberti es otro de los poetas jóvenes en los años de la República y a caballo sobre la guerra civil. Si bien Rafael Alberti no desdeña el empleo del endecasílabo agudo, también es verdad que la frecuencia de este verso en su obra es más bien escasa y quizás podemos ver en ello ya como un avance de lo que será unos años después la restauración de las normas clásica.

Muy conocido es el soneto incluido en Marinero en tierra (1924), su primer libro, dedicado a su antepasada Rosa de Alberti. En ese soneto los versos 1 y 4 de cada cuarteto son endecasílabos agudos:

\footnotetext{
Rosa de Alberti allá en el rodapié del mirador del cielo se entreabría, pulsadora del aire y prima mía, al cuello un lazo blanco de moaré.

El barandal del arpa, desde el pie hasta el bucle en la nieve, la cubría. Enredando sus cuerdas verdecía, alga en hilos, la mano que se fue.
}

Otro endecasílabo agudo aparece en Cal y Canto (1927) expresando la añoranza de Cádiz que acompañó al poeta durante toda su vida:

Yo pienso en mí. Colegio sobre el mar. 
En la sección "Cármenes" de Arión (Versos sueltos del mar), incluído en Pleamar (1942-1944), se lee en el poema 9:

Pensaba en ella. Y me la vi venir

y en 15:

Te acercaste diciéndome: ;Yo soy!

De Entre el clavel y la espada, sección "Del pensamiento en un jardín", recogemos este otro endecasílabo agudo en el que un esdrújulo inicial viene a compensar en cierto modo el peso brusco del agudo final:

\section{pálida era mi madre, $y$ carmesí}

El bello libro $A$ la pintura publicado durante su residencia en Argentina (1948), ofrece, aunque también escasos, algunos ejemplos del verso que buscamos; los que siguen pertenecen al poema "Velázquez" y son los siguientes:

como soy realmente o como tú... cuando decía: Voy al Prado, voy...

si es montaña, si es nieve, si es azul?

Otros dos se encuentran en poemas dedicados a colores. En el poema "Negro" está éste:

vaporosa en la mano de Manet

y en el poema "Blanco" este otro:

feliz de estar en todo, porque soy...

Estos ejemplos corroboran lo escaso de la frecuencia del endecasílabo agudo en este poeta que, como otros, han utilizado a menudo los agudos en posición final en versos menores o en alejandrinos.

Juan Gil-Albert ha sido uno de los poetas que no han gozado 
en vida del reconocimiento que merecía y que la generación actual trata de rescatar como uno de los valores seguros de los años de antes y de después de la guerra civil. Nos ceñimos en la búsquedad de endecasílabos agudos a su libro Fuentes de la constancia $^{31}$ que es libro clave en su obra. El verso dominante en esta obra es precisamente el endecasílabo blanco, pero los de tipo agudo son también escasos. Hemos encontrado ocho de ellos, uno de los cuales, en el poema "Idilios" tiene final monosílabo:

como insigne reclamo de la sed

Otro, por estar en situación de sinalefa, su final bisílabo puede considerarse como vocablo de sílaba única:

Sólo si se ha cumplido con la edad ("La Tarde")

Dos tienen la misma palabra en posición final siendo además versos contiguos:

brillaba el rumoroso mar azul, arriba el luminoso cielo azul ("Alicante")

Los restantes utilizan trisílabos. Son los que siguen:

del que nada se puede precisar y que como un gran dueño patriarcal cual si una incitación muy familiar este voluble atuendo corporal
("El azul”)

("El domingo")

("Refinamiento del campo")

("Las Transformaciones")

Miguel Hernández ${ }^{32}$ debió estar en cuanto se refiere al aspecto formal, más próximo a las tendencias que se impondrían después. No hay en El rayo que no cesa ningún endecasílabo agudo, como tampoco lo hay en el también libro de sonetos de

\footnotetext{
${ }_{31}$ JuAn Gil-albert, Fuentes de la constancia, Madrid, Cátedra, 205. Edición de José Carlos Rovira, 1984.

32 Aunque no todos los poetas de que tratamos aquí están incluidos en ella, conviene consultar Poesía española 1935-2000, Edición de CARMElo GuIllÉn Acosta, Barcelona, Editorial Casals, 2000 y varias ediciones posteriores. Se encontrarán en esta obra un interesante estudio de las características de cada generación y una antología de los poetas más representativos de cada una de ellas.
} 
Francisco Pino, Espesa rama, escrito por los mismos años.

Otro de los poetas cuyo aprecio va creciendo es Luis Rosales quien, quizás por los compromisos políticos de su juventud, ha tenido un eco menor. Las generaciones actuales tienden a reconocer sus merecimientos. Precisamente esos compromisos pueden hacernos creer que Rosales estaba más conforme con el neoclasicismo ya perceptible en la poesía de esos años y posteriores, y sin embargo el empleo del endecasílabo agudo es en él mucho más frecuente que en los poetas que venimos viendo desde Jorge Guillén.

En sus Rimas, no falta este tipo de verso.

El poema "El mundo pictórico de Manolo Rivera es anterior al paraíso" se compone de nueve cuartetos de los cuales el 5, el 6 y el 8 tienen rimas agudas. Citamos la estrofa quinta:

Crece el cuadro de atrás hacia delante,
la pintura va haciéndose espacial
y ves brillar las olas con la sal
que es la forma del agua principiante...

El titulado "Ahora y en la hora de nuestra muerte" es un romance en endecasílabos y sus versos pares riman en asonante -ó. Son catorce endecasílabos agudos. El poema pricipia así:
Cuando los ojos se me queden secos como un campo de esparto, cuando no puedan mirar pero recuerde, cuando la imagen de tu rostro sea anterior a haberte conocido, y en la era el trigo haya perdido su color...

También en cuartetos, como el citado más arriba, se ha escrito el poema "Citada con la luz"; son siete cuartetos, tres de los cuales tienen dos versos agudos en cada uno. El segundo dice así:

El cielo ceniciento se hace pis

y la œnothera biennis está abriendo, primero va el pistilo apareciendo, tiene un color ligeramente gris. 
"Primavera en estatua" está compuesto de dieciocho cuartetos, ocho de los cuales tienen rimas agudas, o sea, para este poema 16 endecasílabos agudos; la rima aguda se aplica en los versos 1 y 4 en seis cuartetos, y cuatro de ellos tienen monosílabos en posición final. Escogemos uno de estos como ejemplo:

Lo que han visto tus ojos no se ve,

la luna está aprendiendo a ser morena, y hay que tranquilizar mucho a la arena que está cansada ya de estar de pie.

Los monosílabos en rima en este poema son pez, vez, ve, pie, yo, Miró.

Como se ve la frecuencia de endecasílabos agudos en las Rimas de Luis Rosales es elevada en proporción con el número de versos que componen el libro.

A Ramón de Garciasol ya se le puede considerar como poeta de la generación de posguerra por haber publicado la parte más considerable de su obra en los años posteriores a 1939. Hemos seleccionado dos de sus libros para rastrear en ellos los endecasílabos agudos. Son Apelación al tiempo (1968) y Decido vivir (1976). Su empleo es muy escaso, en parte porque algunos de sus libros están escritos en verso sin medida pero asonantados. Tampoco aparecen, o muy pocos, en sus poemas de verso regular.

Otro poeta representativo de esa época es José Suárez Carreño que tuvo cierta nombradía a raíz de la publicación de su libro Edad de Hombre, premio Adonáis en 1943. Es un libro compuesto de sonetos de estructura rigurosa en los que no parece ningún endecasílabo agudo.

Otro tanto se puede decir del creador y director de la revista Garcilaso, José García Nieto, iniciador de aquella "segunda primavra del endecasílabo".

Otros poetas más próximos a nuestros día, utilizan el endecassílabo agudo aunque no de manera insistente. Carlos Murciano en Música de la sangre (Antología de sonetos 1950-2000) ) $^{33}$ incluye uno con rimas agudas en los cuartetos. Es el que se titula

$\overline{33}$ In Colección Las dos orillas, El Salvador, 2002. 
"Sisifo"empieza con este verso:

Bajo la piel me palpo lo que soy

En Oda en la ceniza, Las monedas contra la losa, de Carlos Bousoño $^{34}$ se ha empleado el endecasílabo agudo en el poema "Canción para un poeta viejo" en una serie de pareados aconsonantados agudos, salvo el $2^{\circ}$ y el $4^{\circ}$ :

Muy cerca de la vida. Así tu hablar.

Llegaste a viejo cual se llega al mar.

Azotado del viento y de la edad

fuiste la vida y la serenidad.

Conocimiento fue tu reposar.

Llegaste a viejo cual se llega al mar.

Llegaste a viejo cual se llega a ser

la luz delgada del amanecer.

La luz delgada del saber callar

del saber conocer y desear.

del saber esperar, callar, seguir

hasta las olas del saber vivir

Hasta las olas del saber amar profundamente y como es quieto el mar.

$Y$ asi tu ser, escrito en agua y sal

$y$ en viento fue, $y$ en todo lo inmortal.

Otros aparecen diseminados en su obra en poemas a veces de versos de varia medida. Así en el poema "La prueba":

o una locomotora o un jazmín

o en el poema "El mundo: palabras":

cuenta de tu quehacer final. Nada quedó. [...]

hacia una tenue y dulce claridad

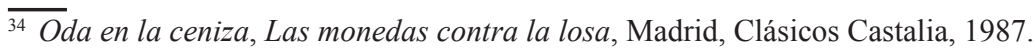


Terminamos este trabajo presentando ejemplos encontrados en poetas de época ya reciente cuyas obras ofrecen endecasílabos agudos en poemas regulares o en otros de estructura libre. Estos ejemplos parecen indicar que la poesía actual vuelve de nuevo al empleo del endecasílabo agudo, no de modo sistemático, naturalmente, pero sí con la libertad de quienes no sienten ya el peso de la tradición.

Los dos poetas que siguen han alcanzado una obra considerable; son Antonio Gamoneda y Antonio Carvajal. El tercero, Rafael Juárez, de obra aunque menos abundante, no es por ello menos interesante.

Un soneto de Antonio Gamoneda de su libro Sublevación inmóvil (1960) tiene los versos centrales de los cuartetos en versos agudos:
Esta es la tierra donde el sufrimiento es la medida de los hombres. Dan pena los condes con su fiel faisán y los cobardes con su fiel lamento.

Otros versos espigados en sus libros son los siguientes, algunos de ellos incluídos en poemas de formas variadas:

Y comprenderlos como a un solo ser

que algo más grande y más real que yo a la belleza y la necesidad a estar contigo en paz y a estar en paz mirar al fondo de mi corazón agua y semillas en el corazón sólo tú puedes soportar, vivir siempre en belleza, nunca en libertad
(Blues castellanos, 1982, "Después de veinte años") (Ibid.) (Id., "Invierno")

(Id., "Amor") (Id., "Geología") (In Pasión de la mirada)

que son, estos últimos, dos endecasílabos agudos contiguos.

Del libro Raso milena y perla, de Antonio Carvajal ${ }^{35}$ hemos recogido los que siguen:

Y el Arte nos dará su bendición ("Cita y glosa")

$\overline{35}$ Valladolid, Fundación Jorge Guillén, Colección “Cortalaire”, 1992 
sobre las negras plumas a la vez

Fundirse lentamente en un metal

No tener corazón, sed de saber ni de tener, ni de tenerse. Estar

deseos que durmieron. $Y$ dormir

en volumen perenne, en fundición $y$ fundación de la belleza luego
(Id. 2)

("Variaciones, formas de un pensamiento)

(Epístola y coplas)

Nótese el juego de variantes fundación / fundición y su posición en los versos.

su trabajo y su amor. Yo me quedé

atado a las palabras y ahora tú

En el verso que sigue las posiciones inicial y final están ocupadas por esdrújulo y agudo:

estímulo y motivo de canción $y$ danos en su luz tu claridad. y no distingue cielo de pared. con el culo pegado a la pared.
(Id.)

("Dos preguntas, una súplica")

("Dos instantes de Velázquez") (Id.)

De Canciones y sonetos, de Rafael Juárez ${ }^{36}$ citamos los siguientes. En el primer ejemplo se han utilizado vocblos agudos en posiciones final e inicial de versos contiguos (luz / atroz)

qué significa paz endeble, luz atroz, misericordia.

(Fábula de fuentes)

En el soneto "La herida", los versos pares de los serventesios (A-B-A-B) son agudos. El primer cuarteto es:

$A$ veces pienso dar forma de vida a esta disposición a no escribir;

$\overline{36}$ Estepa, Ilmo. Ayuntamiento, 1995 
olvidar la poesía, pues se olvida otra cosa cualquiera por vivir.

Los tercetos riman en agudo el 9-11 y 13:

$Y$ es que a veces quisiera no saber lo que pasa, o nunca haber sabido lo dulce que el silencio puede ser.

Porque ya para siempre estaré herido, condenado a decir y a no entender, como un niño que hablara del olvido.

En el soneto "De luz contraria", los versos pares de los cuartetos también son agudos. El primero de ellos es éste:

Bulle detrás la noche y sus engaños.

Delante el día se prepara cruel.

Esla hora del alba. En el dintel

del tiempo surgen pájaros extraños.

En el soneto "Otoño", los versos 1-4-5-8 riman en -or: En los tercetos los versos 9 y 12 riman en - al. Son seis agudos en catorce versos. Copiamos el primer cuarteto:

Pero existe el otoño. Es el color que se va de las hojas y las deja muertas, los sentimientos en madeja, algo que ya no es vivo y no es licor

Conviene resaltar la frecuencia relativa de agudos en este libro de Canciones y sonetos, por tratarse de un conjunto breve, lo que parece confirmar este renacer del endecasílabo agudo en las generaciones más próximas a hoy.

El verso endecasílabo agudo desdeñado por los tratadistas de los siglos XVI y XVII, dejó de emplearse casi de modo general. Hubo tolerancia en su empleo en poemas burlescos o satíricos o en ejercicios métricos que permitían a los autores incluir, por ejemplo, rimas internas. Ejemplos de este tipo de poemas, 
generalmente sonetos, pueden verse en La Pícara Justina, de Francisco López de Úbeda, y tambien en Gerardo Lobo y Tomás Iriarte en sonetos recogidos en Poesía del siglo XVIII, ed. Jonh H. R. Polt, Castalia, 65, 1994. En el siglo XIX la octava bermudiana recupera el endecasílabo agudo que será cultivado especialmente por Zorrilla. Ya en el siglo xx se detecta la tendencia a evitar ese tipo de verso hasta que la "Juventud creadora" guiada por José García Nieto en la revista Garcilaso propone restaurar los cánones clásicos e inaugurar la "segunda primavera del endecasílabo", aunque, como se ha visto, no todos los colaboradores de la revista respetan esa tendencia. Los poetas que viven a caballo de la guerra civil aplican la misma norma porque el ambiente general iba en el mismo sentido. Poetas como Miguel Hernández y Francisco Pino, no utilizan el endecasílabo agudo en los sonetos de El rayo que no cesa o de Espesa rama.

Tres grandes poetas se separan de la tradición y de las tendencias del momento: Miguel de Unamuno, Juan Ramón Jiménez y Jorge Guillén quienes no sólo introducen en sus obras endecasílabos agudos, sino que por su situación en el poema (El Cristo de Velázquez), por la posición de vocablos agudos en el interior del verso, por su colocación bajo los acentos, por la contigüidad con vocablos esdrújulos y otros aciertos, obtienen de ese verso una alta densidad expresiva. Juan Ramón Jiménez recurre al endecasílabo agudo sobre todo en sus libros finales, identificándo el verso con su pensamiento, haciendo de él instrumento de expresión de su estética final. Jorge Guillén ha sembrado su obra de endecasílabos agudos, también con clara sabiduría de las posibilidades que se le ofrecían.

Las generaciones posteriores utilizan ese verso de modo desigual. Algunos poetas recurren al él, otros lo ignoran. Hay un periodo que podría dcirse de indiferencia hacia ese verso que es acogido o no según el talante del poeta o la necesidad de dar a su verso cierta contundencia. Lo han empleado Luis Rosales, Carlos Bousoño y otros pero sin continuidad en su uso. En cambio se nota en las generaciones más recientes una mayor libertad en el empleo de ese verso que reaparece con cierta frecuencia en los poetas que todavía hoy siguen dando a la poesía su ofrenda personal, como Antonio Carvajal, por ejemplo. Sí es cierto que 
desde las experiencias de Unamuno, J. R. Jiménez y Jorge Guillén, el endecasílabo agudo ha recuperado su dignidad y los poetas posteriores ya no sienten aquel desdén y aquel desafecto que tuvieron con él los poetas de los siglos pasados.

Este sondeo nos ha llevado a dar a este trabajo cierto aspecto de repertorio, de catálogo, pero nos ha parecido mejor presentar ejemplos abundantes, precisamente para que se pueda entender hasta qué punto los poetas han desmentido aquella afirmación de Vicente Gaos citada el principio. 